\title{
KANDUNGAN KARBON SERASAH DAUN KUMA (Palaquium luzoniense) DI KAWASAN HUTAN LINDUNG NANGA-NANGA PAPALIA SULAWESI TENGGARA
}

\section{CARBON CONTENTS OF KUMA LEAF (Palaquium luzoniens Vid.) IN PROTECTED FOREST AREAS NANGA-NANGA PAPALIA KENDARI CITY SOUTHEAST SULAWESI}

\author{
Clara Sesilia Mekuo ${ }^{(1)}$, Sitti Wirdhana Ahmad ${ }^{(2)}$, Muhsin $^{(3)}$ \\ (1) Program Studi FMIPA Universitas Halu Oleo, Kendari \\ ${ }^{(2,3)}$ Dosen Program Studi, Jurusan Biologi FMIPA Universitas Halu Oleo, Kendari \\ (2) Corresponding author email: wirdhanaaxtalora@yahoo.com
}

\begin{abstract}
Abstrak
Penelitian ini bertujuan untuk mengetahui kandungan karbon serasah daun Kuma (Palaquium luzoniense Vid.) di kawasan Hutan Lindung Nanga-Nanga Papalia Kota Kendari Sulawesi Tenggara. Penelitian ini merupakan penelitian eksplorasi dengan menentukan 3 stasiun pengambilan sampel berdasarkan pengamatan ketersediaan tumbuhan Kuma (Palaquium luzoniense Vid.) dengan ketinggian yang berbeda yakni Titik I (ketinggian $\pm 223 \mathrm{mpdL}$ ), Titik II (ketinggian $\pm 246 \mathrm{mdpL}$ ) dan Titik III (ketinggian \pm 276 mdpL). Pengambilan serasah daun Kuma (Palaquium luzoniense Vid.) dilakukan secara purposive sampling. Kandungan karbon diperoleh dengan cara mengalikan nilai kadar karbon dan nilai biomassa serasah daun. Hasil perhitungan kandungan karbon sebesar $5501,565 \mathrm{gr} / \mathrm{m}^{2} / \mathrm{bulan}$.
\end{abstract}

Kata kunci: Kuma (Palaquium luzoniense Vid.), Serasah Daun, Kandungan Karbon, Hutan Lindung Nanga-Nanga

\begin{abstract}
This study aimed to determine the carbon content of Kuma leaf litter (Palaquium luzoniense Vid.) in Nanga-Nanga Papalia Protected Forest area at Kendari Southeast Sulawesi. This study was an exploration research by determined three station sampling based on obsenvation of availability Kuma (Palaquium luzoniense Vid.) species with differet hight s.i.e first point (altitude of $\pm 223 \mathrm{mpdL}$ ), second point (altitude of $\pm 246 \mathrm{mdpL}$ ) and third point (altitude $\pm 276 \mathrm{mdpL}$ ). Sampling of Kuma leaf litter (Palaquium luzoniense Vid.) used purposive sampling. The carbon content is obtained by multiplying \%carbon content and biomass values. The result showed that carbon content of Kuma leaf litter (Palaquium luzoniense Vid.) of $5501.565 \mathrm{~g} / \mathrm{m} 2$ / mont.
\end{abstract}

Keywords: Kuma (Palaquium luzoniense Vid.), Leaf Litter, Carbon Content, NangaNanga Papalia Protected Forest 


\section{PENDAHULUAN}

Hutan adalah suatu asosiasi tumbuhan dimana pohon-pohon atau tumbuhan berkayu lainnya menempati wilayah yang luas dan keberadaannya cukup dominan sehingga mampu menciptakan iklim yang berbeda antara wilayah disekitar hutan dengan wilayah yang jauh dari hutan (Soetrisno, 2000). Keberadaan hutan berfungsi sebagai sistem hidrologi, menciptakan iklim mikro, menjaga keseimbangan oksigen $\left(\mathrm{O}_{2}\right)$ dan karbon dioksida $\left(\mathrm{CO}_{2}\right)$, mengurangi polutan, meredam kebisingan, dan menambah nilai estetika dan keasrian sehingga berdampak positif terhadap kualitas lingkungan dan kehidupan masyarakat. Selain itu, hutan juga berfungsi sebagai tempat penyimpanan karbon (Indriyana, 2014).

Sulawesi merupakan salah satu pulau besar di Indonesia, yang secara biogeografi termasuk dalam kawasan Wallacea. Sulawesi Tenggara menjadi bagian dari wilayah Pulau Sulawesi yang memiliki keanekaragaman flora cukup tinggi yang tersebar di berbagai tipe vegetasi (BKSDA Sultra, 2006). Salah satu kawasan hutan lindung yang ada di Provinsi Sulawesi Tenggara yaitu Hutan Lindung NangaPalaquium luzoniense Vid. atau yang di Sulawesi Tenggara ini disebut nanga Papalia (Komunitas Teras, 2008).

Kawasan Hutan Lindung Nangananga Papalia merupakan kawasan hutan yang berada di Kota Kendari. Secara hukum Kawasan Hutan Lindung Nanga-nanga ditetapkan oleh Menteri

Kehutanan melalui keputusan No.639/Kepts/um/9/ 1982 pada tanggal 01 September 1982. Kemudian dilakukan perubahan melalui Keputusan Menteri Kehutanan No. 426/Kepts-II/1997 pada tanggal 30 Juli 1997 tentang penetapan kawasan Hutan Lindung Nanga-nanga sebagai kawasan hutan tetap dengan fungsi lindung dan hutan produksi yang keberadaannya tidak hanya menjadi ciri khas Kota Kendari, namun juga berfungsi sebagai daerah serapan air (Departemen Kehutanan, 2002).

Berdasarkan hasil penelitian yang dilakukan oleh Rahardi (2014) di Kawasan Hutan Lindung Nanga-Nanga Papalia tersusun atas 53 jenis tumbuhan golongan pohon yang terkelompok dalam 27 famili dan terdistribusi menurut tingkat pertumbuhan semai, pancang, tihang dan pohon. Salah satu jenis tumbuhan dari 53 jenis tersebut terdapat pohon kuma (Palaquium luzoniense Vid.). dengan kuma memiliki nama lain yaitu Nyatoh (Untuk daerah Jawa dan 
sekitarnya). Nyatoh merupakan nama dagang untuk kayu dari genus Palaquium dan Payena yang tumbuh di lingkungan hutan hujan di Asia Tenggara, khususnya di Indonesia dan Filipina. Palaquium luzoniense merupakan jenis kayu hutan yang bernilai ekonomis berfungsi memasok kayu yang digunakan secara lokal dan diperdagangkan (Pusat Penelitian dan Pengembangan Hasil Hutan, 2008).

Menurut Hairiah dan Rahayu (2007) proporsi terbesar penyimpanan karbon di daratan umumnya terdapat pada komponen pepohonan. Kemampuan tumbuhan dalam penyerapan karbon untuk mengurangi efek gas rumah kaca dipengaruhi oleh ketersediaan biomassa yang terdapat di dalamnya. Pendugaan biomassa sangat penting untuk mengkaji cadangan karbon dan efek dari deforestasi serta penyimpanan karbon dalam keseimbangan karbon (Kettrings dkk., 2001).

Mengacu pada hal tersebut penelitian mengenai kandungan karbon serasah daun kuma (Palaquium luzoniense Vid.) menjadi penting untuk dilakukan. Hasil penelitian diharapkan menjadi informasi tentang kandungan karbon salah satu jenis tumbuhan di Hutan Lindung Nanga-Nanga Papalia Kendari Sulawesi Tenggara.

\section{METODE PENELITIAN}

\section{Alat dan Bahan}

Alat dan bahan yang digunakan pada penelitian ini yaitu GPS (Global Position Systema), lux meter, hygrometer, rol meter, litter trap, neraca analitik, oven, eksikator, blender besi, pinset, cawan porselen, serasah daun kuma (Palaquium luzoniense), tali nilon, jaring/ net diameter $0,5 \mathrm{~m}$, litter bag, kantong sampel, dan akuades.

\section{Prosedur Penelitian}

\section{Penetuan Lokasi Penelitian}

Penetuan lokasi penelitian berdasarkan pengamatan ketersediaan tumbuhan kuma (Palaquium luzoniense Vid.) dengan ketinggian tempat yang berbeda. secara purposive sampling (pohon kuma berdiameter diatas $20 \mathrm{~cm}$ ) yang dibagi dalam tiga lokasi yaitu titik I dengan titik kordinat (S: $04^{0} 39{ }^{\prime} 36,7$ "dan E: $\left.121^{0} 54^{\prime 24}, 1^{\prime \prime}\right)$, ketinggian $\pm 223 \mathrm{mdpl}$, titik II dengan titik kordinat (S: 04 $39^{\prime} 41,0^{\prime \prime}$ dan $\left.\quad E: \quad 122^{0} 54^{\prime} 19,7^{\prime \prime}\right)$, ketinggian $\pm 246 \mathrm{mdpl}$, titik III dengan titik kordinat (S: $04^{0} 39^{\prime} 42,1^{\prime \prime}$ dan E: $\left.122^{0} 54^{\prime} 39,1^{\prime \prime}\right)$, ketinggian \pm 276 mdpl.

\section{Pemasangan Litter Trap}

Pemasangan 1 perangkap serasah (litter trap berukuran 2×2 m) setiap pohon berdasarkan ketinggian 
tempat secara purposive sampling dan ditempatkan pada ketinggian $2 \mathrm{~m}$ di atas permukaan tanah menggunakan penyangga kayu.

\section{Faktor Lingkungan}

Pengukuran faktor lingkungan yang dilakukan pada penelitian ini meliputi pengukuran intesitas cahaya, suhu udara, kelembapan udara, $\mathrm{pH}$ tanah, kelembaban tanah, data curah hujan dan kecepatan angin (data sekunder).

\section{Preparasi Sampel}

Sampling dilakukan setiap bulan, kemudian serasah daun kuma dipisahlkan dan ditimbang berat basah serta serta berat kering (setelah di oven pada suhu $85^{\circ} \mathrm{C}$ selama 48 jam. Selanjutnya tiap sampel serasah daun kuma didestruksi dengan menggunakan blender hingga menjadi serbuk untuk dianalisis kandungan karbonnya. Analisis kadar karbon dilakukan dengan menggunakan ASTM (American Society for Testing Material) D-3175 (dalam Sutapa dan Irawati 2006), dimana kadar karbon contoh uji merupakan hasil pengurangan 100\% terhadap kadar zat terbang dan kadar abu.

a. Kadar zat arang penentuan zat terbang yang digunakan berdasarkan ASTM D 5832-98 (dalam Sutapa dan Irawati, 2006).
Kadar zat terbang dinyatakan dalam persen (\%) dengan rumus:

Kadar zat terbang $=\underline{\text { Kehilangan Berat Contoh }} \times 100$ Berat Contoh Uji Bebas Air

b. Penentuan kadar abu menggunakan ASTM D 2866-94 (dalam Sutapa dan Irawati, 2006).

Kadar abu $=$ Berat sisa contoh uii $\times 100$ Berat Contoh Uji Bebas Air

c. Kadar karbon tetap ditentukan berdasarkan Standar Nasional Indonesia (SNI) 06-3730-1995 sebagai berikut:

Kadar karbon $=100 \%-$ Kadar Zat Terbang - Kadar Abu

Kandungan Karbon dihitung dengan rumus berikut:

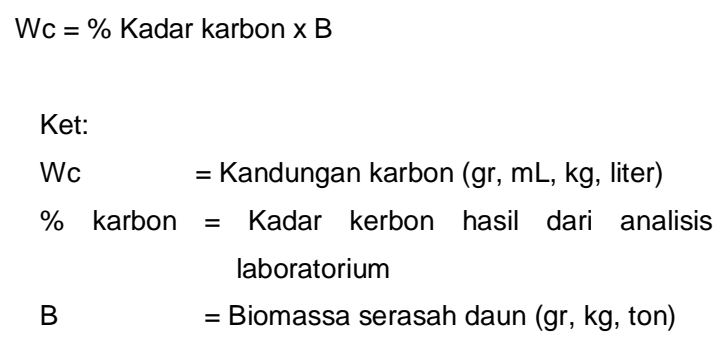

\section{HASIL DAN PEMBAHASAN}

Kandungan karbon pada serasah daun kuma (Palaquium luzoniense Vid.) di hutan Lindung Nanga-Nanga Papalia selama bulan Februari-Mei 2017 mengalami perbedaan setiap bulannya seperti pada Gambar 1. 


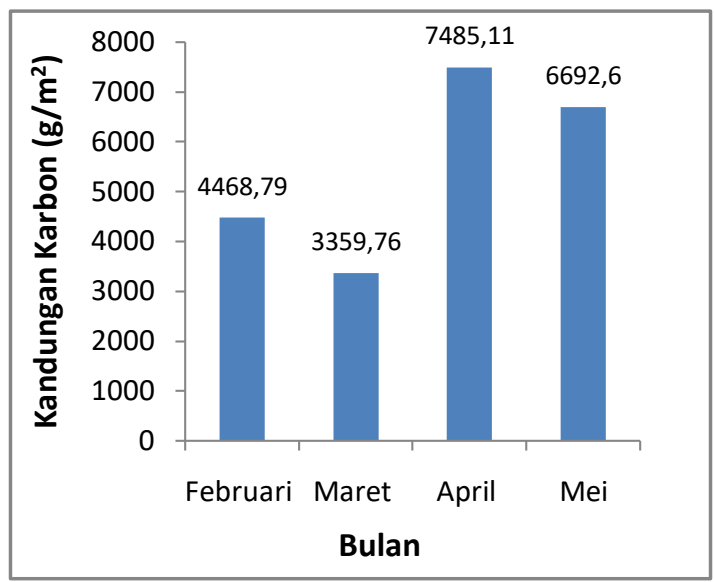

Gambar 1. Kandungan karbon serasah selama bulan Februari-Mei 2017

Tabel tersebut menunjukkan nilai tertinggi dan terendah kandungan karbon selama 4 bulan. Faktor yang mempengaruhi tinggi dan rendahnya kandungan karbon pada bulan April yaitu nilai biomassa yang tinggi pada bulan April $\left(99,36 \mathrm{gr} / \mathrm{m}^{2}\right)$ rendahnya nilai yang terdapat pada bulan Maret $\left(47,6 \mathrm{gr} / \mathrm{m}^{2}\right)$.

Berdasarkan pada 3 titik stasiun kandungan karbon serasah daun kuma (Palaquium luzoniense Vid.) pada setiap lokasi penelitian di Hutan Lindung Nanga-Nanga Papalia Kota Kendari yang tertinggi terdapat pada titik II dengan nilai sebesar 6125,88 gr dan kandungan karbon serasah daun kuma (Palaquium luzoniense Vid.) terendah yaitu pada Titik I dengan nilai yang diperoleh 4739,58 gr seperti pada Gambar 2.

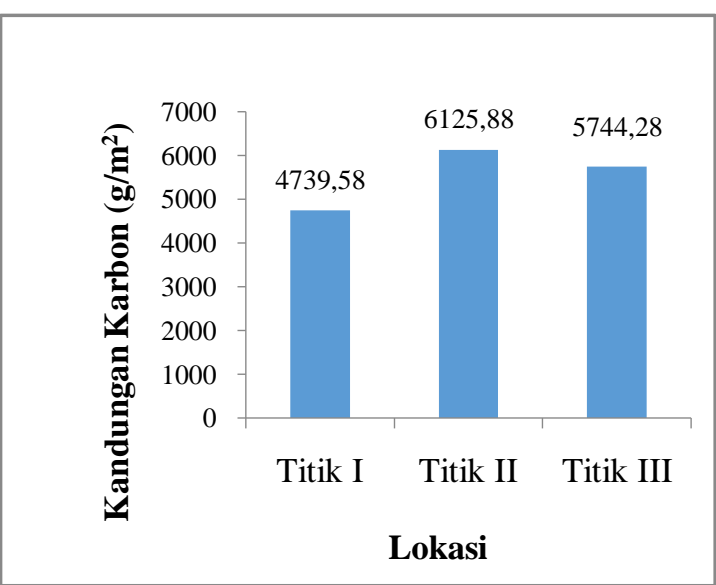

Gambar 2. Kandungan karbon serasah pada 3 titik stasiun

Faktor yang mempengaruhi tinggi dan rendahnya kandungan karbon pada titik II dan titik I yaitu nilai biomassa yang juga tinggi pada Titik II dan rendah Titik I. Hal ini menunjukkan adanya hubungan yang sangat kuat dan positif antara biomassa dengan kandungan karbon pada serasah daun kuma (Palaquium luzoniense Vid.).

Terdapat hubungan yang sangat kuat dan positif ketika terjadi peningkatan biomassa maka akan terjadi peningkatan kandungan karbon pada serasah daun. Besarnya kandungan karbon dipengaruhi oleh kandungan bahan organik sehingga kandungan karbon berkorelasi positif dengan bahan organik tersebut. Makin besar kandungan bahan organik organik maka potensi karbon akan semakin besar (Yamani, 2013). 


\section{PENUTUP}

\section{Kesimpulan}

Kandungan karbon serasah daun kuma (Palaquium luzoniense Vid.) di kawasan Hutan Lindung Nanga-nanga Papalia Kota Kendari Sulawesi Tenggara sebesar 5.501,565 $\mathrm{gr} / \mathrm{m}^{2} /$ bulan

\section{Saran}

Saran yang dapat diajukan penulis melalui penelitian yaitu perlu adanya penelitian lebih lanjut mengenai kandungan karbon serasah daun Kuma (Palaquium luzoniense Vid.) di Kawasan Hutan Lindung Nanga-Nanga Papalia Kota Kendari Sulawesi Tenggara pada periode bulan yang berbeda.

\section{DAFTAR PUSTAKA}

BKSDA Sultra, 2006, Informasi Kawasan Konservasi Propinsi Sulawesi Tenggara, BKSDASultra, Kendari.

Departemen Kehutanan, 2002, Data dan Informasi Kehutanan Propinsi Sulawesi Tenggara, Pusat Inventarisasi dan Statistik Kehutanan, Badan Planologi Kehutanan, Jakarta.

Hairiah K, dan Rahayu S., 2007, Pengukuran Karbon Tersimpan di Berbagai Macam Penggunaan Lahan, University of Brawijaya, Bogor.

Indriyana, N.D., 2014, Analisis Biomassa dan Kandungan Karbon pada Jenis Serasah Daun Tanaman Hutan Kota di Arboretum Arsitektur Lankap
IPB, Skripsi, Institut Pertanian Bogor, Bogor.

Afifah, N., 2010, Analisis Kondisi dan Potensi Lama Fermentasi Medium Kombucha (Teh, Kopi, Rosela) dalam Menghambat Pertumbuhan Bakteri Patogen (Vibrio cholerae dan Bacillus cereus), Skripsi, Jurusan Biologi, Fakultas Sains dan Teknologi (UIN) Maulana Malik Ibrahim, Malang.

Kettrings, Q.M., Coe, R., Noordwijk, M., Ambagau, Y., dan Palm, C.A., 2001, Reducing Uncertainty in The Use of Allometric Biomass Equation for Predicting Above Ground Tree Biomass in Mixed Secondari Forest. Jurnal Forest Ecology and Management.

Komunitas Teras, 2008, Pemetaaan dan Inventarisasi Potensi Kawasan Hutan Nanga-nanga Papalia, Laporan Akhir Kegiatan Bapeda Sultra, Kendari.

Pusat Penelitian dan Pengembangan Hasil Hutan (P3HH), 2008, Petunjuk Praktis Sifat-sifat Dasar Jenis Kayu Indonesia, Indonesian Sawmill and Woodworking Association (ISWA), Indonesia.

Rahardi, W., 2014, Komposisi dan Keanekaragaman Jenis Tumbuhan Golongan Pohon di Kawasan Hutan Lindung Nanga-nanga Papalia Kota Kendari Sulawesi Tenggara, Skripsi, Universitas Halu Oleo, Kendari.

Soetrisno, K., 2000, Silvika, Fakultas Kehutanan, Universitas Mulawarman, Samarinda.

Sutapa, J.P.G., dan Irawati D., 2006, Petunjuk Praktikum Energi Biomassa. Laboratorium Energi Biomassa, Jurusan Teknologi Hasil Hutan, 
Universitas Gadjah Mada, Yogyakarta.

Yamani, A., 2013, Studi Kandungan Karbon pada Hutan Alam
Sekunder di Hutan Pendidikan Mendiangin Fakultas

Kehutanan Unlam, Jurnal Hutan Tropis, 1(1) Hal 85-91 